(C) The Author(s) 2016. This is an Open Access article, distributed under the terms of the Creative Commons Attribution licence (http://creativecommons. org/licenses/by/4.0/), which permits unrestricted re-use, distribution, and reproduction in any medium, provided the original work is properly cited.

\title{
Avalanche character and fatalities in the high mountains of Asia
}

\author{
D.M. MCCLUNG \\ Department of Geography, University of British Columbia, Vancouver, British Columbia, Canada \\ Correspondence: D.M. McClung <mcclung@geog.ubc.ca>
}

\begin{abstract}
With the exception of northern India, there are few, if any, consistent data records relating to avalanche activity in the high mountains of Asia. However, records do exist of avalanche fatalities in the region, contained in mountaineering expedition reports. In this paper, I review and analyze statistics of avalanche fatalities (both snow and ice) in the high mountains of Asia (Himalaya, Karakoram, Pamir, Hindu Kush, Tien Shan, Dazu Shan) from 1895 to 2014. The data are stratified according to accident cause, geographical region (Nepal-Tibet (Xizang), Pakistan, India, China, Central Asia), mountain range, personnel (hired or expedition members) and terrain. The character of the accidents is compared with data from North America and Europe. The data show that the important risk components are the temporal and spatial exposure probabilities. It is shown that human actions and decisions govern the pattern of fatal avalanches in the high mountains of Asia.
\end{abstract}

KEYWORDS: avalanches, glacier hazards, snow

\section{INTRODUCTION}

The high mountains of Asia include all the world's mountains with elevations $>7000 \mathrm{~m}$ a.s.l. It can generally be expected that snow and ice cover will be encountered at elevations above $\sim 4800 \mathrm{~m}$. Mountaineering expeditions are the principal human activity in these high mountains. The risk of death is very high while climbing these peaks, but attainment of the summits is highly prized by climbers. In attempts on peaks over $7000 \mathrm{~m}, \sim 4 \%$ of expedition participants die (all causes, including avalanches), compared with $\sim 0.3 \%$ on expeditions to Denali $(6190 \mathrm{~m})$, North America's highest peak, and $0.03 \%$ for heavily glaciated Mount Rainier $(4392 \mathrm{~m}$ ), the highest peak of the Cascade Range, USA (McClung, 2014). The data suggest that peak elevation matters and that expedition climbing is very risky. Salisbury and Hawley (2007) compiled data on mountaineering accidents in Nepal from 1950 to 2006 and concluded that avalanches (272 deaths) and falls (255 deaths) were the chief causes of death there, accounting for $\sim 67 \%$ of total deaths.

For this paper, I have compiled data on $\sim 700$ snow and ice avalanche fatalities (1895-2014) resulting from mountaineering-related activities in the high mountains of Asia, as an extension of my previous paper (McClung, 1981) which contained the records through 1979. Since my previous paper, I have scanned $\sim 5000$ expedition reports to bring the database up to 2014.

The results show that, from a risk perspective, the temporal and spatial exposure parts of the risk matter most, in contrast to North America and Europe. In addition, recent accidents on Mount Everest in spring 2014 (icefall accident (16 deaths)) and spring 2015 (at least 18 deaths reported at base camp from an earthquake-triggered avalanche off Pumori $(7161 \mathrm{~m}))$ have shown that the avalanche risk to mountaineers can significantly affect the fragile economy of Nepal. Both accidents resulted in early termination of the climbing season on the mountain by the Nepalese.

The objective of this paper is to provide information about avalanches in the world's greatest mountain ranges (including what is unique about them), the character of the accidents and remedial measures for improving safety. The data herein apply to mountaineering-related activities and, as such, are not the only records of avalanche fatalities in the countries containing the high mountains of Asia. The Appendix provides a limited, brief summary of avalanche fatalities from India including data from villages and travel in valley bottoms and roads. It shows that the number of fatalities resulting from these activities exceeds those analyzed here.

\section{DATA DESCRIPTION}

The data here consist of information from expedition reports published in alpine journals, magazine articles and other reports as well as on internet websites. McClung (1981) provides information through 1979. The past 1979 information was updated through 2014, mainly by scanning expedition reports published in the American Alpine Journal (AAJ, 1980-2014), and checked with reports from the Alpine Journal and the Himalayan Journal (New Delhi). The data since 1979 consist of documented cases (published expedition reports) and summary data from websites specifically for the $8000 \mathrm{~m}$ peaks (www.8000ers.com; www.en.wikipedia. org/wiki/List_of_deaths_on_eightthousanders). The data for the $8000 \mathrm{~m}$ peaks were cross-checked against my extensive list of references from McClung (1981) to eliminate as many errors as possible. The data here are for the world's ranges containing peaks over $7000 \mathrm{~m}$. The group of 14 peaks over $8000 \mathrm{~m}$ is the best documented and comprises the most highly prized summits for mountaineers. Given the proliferation of expeditions over the last 30 years, the database cannot be considered complete. Many expeditions do not file expedition reports, including, importantly, commercial expeditions which have increased rapidly since 1990 (Salisbury and Hawley, 2007). The descriptor 'at least' should be applied to any numbers reported in this paper. However, there are enough reports and information to provide a useful picture of the accident character.

The data were stratified according to (1) climate region, (2) peak height ( $>8000 \mathrm{~m}, 7000-8000 \mathrm{~m},<7000 \mathrm{~m})$, (3) type of accident ((a) triggered and while climbing, (b) in camps, (c) icefall, (d) unknown) and (4) expedition members or hired personnel (including porters, high-altitude porters). Membership is hugely international, so it is not profitable to 
Table 1. Avalanche (snow and ice) deaths on the $8000 \mathrm{~m}$ peaks during the period 1895-2014, avalanche deaths as percent of the total (1895-2012), and the number of successful ascents per death (1895-2012). The records for total number of ascents are published only through 2012 (www.8000ers.com; www.en.wikipedia.org/wiki/List_of_deaths_on_eightthousanders)

$\%$

Everest $(8850 \mathrm{~m})$ (Nepal-Tibet)
K2 (8611 m) (Pakistan-China)
Kangchenjunga (8586 m) (Nepal-India)
Lhotse $(8516 \mathrm{~m})$ (Nepal)
Makalu $(8463 \mathrm{~m})$ (Nepal-Tibet)
Cho Oyu $(8201 \mathrm{~m})$ (Nepal-Tibet)
Dhaulagiri $(8167 \mathrm{~m})$ (Nepal)
Manaslu (8163 m) (Nepal)
Nanga Parbat (8125 m) (Pakistan)
Annapurna (8091 m) (Nepal)
Gasherbrum I (8068 m) (Pakistan-China)
Broad Peak (8047 m) (Pakistan)
Gasherbrum II (8035 m) (Pakistan-China)

Shisha Pangma (8013 m) (Tibet)

$\begin{array}{rr}76 & 30 \\ 23 & 11 \\ 8 & 3 \\ 3 & 3 \\ 3 & 3 \\ 9 & 4 \\ 35 & 14 \\ 40 & 11 \\ 29 & 9 \\ 42 & 19 \\ 10 & 4 \\ 4 & 3 \\ 4 & 3 \\ 14 & 7\end{array}$

$\begin{array}{rr}27 & 94 \\ 26 & 15 \\ 20 & 35 \\ 23 & 154 \\ 10 & 120 \\ 26 & 392 \\ 51 & 13 \\ 45 & 23 \\ 41 & 12 \\ 64 & 5 \\ 35 & 33 \\ 19 & 101 \\ 19 & 233 \\ 48 & 25\end{array}$

provide counts of members by nationality. Although both hired personnel and members are in the voluntary risk category, there is a difference from a risk perspective since most of the former depend on mountaineering for their livelihood and economic survival, whereas it is purely a sport for the members.

\section{AVALANCHE DEATHS ON $8000 \mathrm{M}$ PEAKS}

The world's fourteen $8000 \mathrm{~m}$ peaks are among the most highly sought-after by climbers. They are all very challenging, typically requiring long periods of risk exposure (months) to reach the summits. The vertical relief from base camps (up to $>3500 \mathrm{~m}$ ) and the extreme altitudes provide high risk exposure. The $8000 \mathrm{~m}$ peaks are the best documented in terms of fatal accidents. Table 1 lists the avalanche fatality characteristics and simple risk indices for this set of peaks.

Table 1 suggests that the peaks of central Nepal (Annapurna, Dhaulagiri, Manaslu) exhibit very high avalanche risk to climbers. The statistics (www.8000ers.com) show that 35 of the Annapurna deaths (13 accidents) occurred on north side routes; although these have been known to be avalanche-prone since the first ascent in 1950, climbers avoid the very steep and difficult south side. On Dhaulagiri, the northeast ridge (first ascent route) accounts for 16 fatalities (8 accidents). On Manaslu, 33 fatalities (8 accidents) occurred on the northeast face (first ascent route). For these peaks (Annapurna massif, Manaslu massif, Dhaulagiri), it seems climbers trade safety for ease of ascent. For Shisha Pangma, the deaths come from a mix of routes, but there appear to be several routes with fairly easy snow climbs prone to avalanche formation.

On Everest, 23 fatalities (13 accidents) occurred on the north side, which has been known since 1922 (7 deaths) to be avalanche-prone, and 53 deaths (17 accidents) on the south side. The 18 base-camp fatalities reported in spring 2015 will bring the Everest total to 94. Shipton (1943) reported that the 1935 and 1936 Everest expeditions were halted due to avalanche conditions below the North Col. He reported a slab avalanche with fracture depth $\sim 1.8 \mathrm{~m}$ and width $400 \mathrm{~m} \sim 60 \mathrm{~m}$ below the col. On Everest, the same pattern as before appears: people prefer ease of ascent over avalanche safety.

The fifth column of Table 1 is calculated as the quotient of number of successful ascents to avalanche deaths (through 2012). It suggests Annapurna, Dhaulagiri, K2 and Nanga Parbat present the highest risk for avalanche deaths using this index.

The Annapurna massif has witnessed 54 avalanche fatalities (Annapurna I (42) + Annapurna South (2) + Annapurna III (8) + Gangapurna (2)). The Manaslu area has seen 64 (Manalsu (40) + Himalchuli (6) + Kang Guru (18)). The area south of the Annapurna massif has the highest precipitation in Nepal and also the highest in the Himalaya (Dhar and Nandargi, 2005). The Manaslu area is just to the east, and Dhaulagiri (35 deaths) is just west, of Annapurna. Thus, high snowfall may partially explain the concentration of deaths.

\section{HIRED PERSONNEL VERSUS EXPEDITION MEMBERS}

Overall on the $8000 \mathrm{~m}$ peaks, 118 of the 300 avalanche deaths $(40 \%)$ were of hired personnel. On Everest, however, 55 of the 76 snow and ice avalanche deaths (72\%) were of hired personnel. Other peaks with a high number and percentage of hired personnel deaths include Dhaulagiri (40\%); Nanga Parbat (38\%), Manaslu (30\%) and Annapurna (33\%). On Cho Oyu, five of nine deaths were of hired personnel (56\%).

Salisbury and Hawley (2007) provide statistics for Nepal (1950-2006) on participation rates for members and hired personnel above base camp for the pre- and post-monsoon seasons. They list 47340 total participants, with hired personnel being $22 \%$ of the total for $<7000 \mathrm{~m}$ peaks, $25 \%$ for $7000-8000 \mathrm{~m}$ peaks and $34 \%$ for $>8000 \mathrm{~m}$ peaks. Avalanche deaths for all peaks in Nepal (1950-2006) were 170 for members $(62.5 \%)$ and 102 for hired personnel $(37.5 \%)$, similar to the $8000 \mathrm{~m}$ peaks as above. When adjusted for participation rate above base camp, they found $0.5 \%$ for members and $0.7 \%$ for hired personnel (data for all 
Table 2. Accident type versus death toll from documented cases (1895-2014)

\begin{tabular}{lcrcr}
\hline Accident type & \multicolumn{2}{c}{ All peaks } & \multicolumn{2}{c}{8000 m peaks } \\
& $\begin{array}{c}\text { Number of } \\
\text { deaths }\end{array}$ & $\%$ & $\begin{array}{c}\text { Number of } \\
\text { deaths }\end{array}$ & $\%$ \\
\hline Icefall & 112 & 18 & 59 & 27 \\
Improper camp & 277 & 45 & 75 & 35 \\
Triggered/climbing & 184 & 30 & 76 & 35 \\
Unknown & 43 & 7 & 6 & 3 \\
\hline
\end{tabular}

seasons). However, in the fall (post-monsoon) season, they found $0.64 \%$ for members and $1.1 \%$ for hired personnel. Thus, the rate for hired personnel based on participation rate was nearly double that for members in the fall season compared to all seasons combined. Dhar and Nandargi (2005) showed that the overall precipitation rate in Nepal is higher post-monsoon than pre-monsoon, which may partially explain the higher death rates post-monsoon.

\section{AVALANCHE DEATHS ON ALL HIGH PEAKS OF ASIA FROM DOCUMENTED CASES}

I found 92 separate accidents in expedition reports from the American Alpine Journal (AAJ, 1980-2014). These reports yielded 111 deaths (45 accidents) from $>8000 \mathrm{~m}$ peaks, 151 deaths (36 accidents) from $7000-8000 \mathrm{~m}$ peaks, and 58 deaths ( 11 accidents) from $<7000 \mathrm{~m}$ peaks. These data imply 2.5 deaths per accident ( $>8000 \mathrm{~m}$ peaks), 4.2 deaths per accident (7000-8000 $\mathrm{m}$ peaks) and 5.3 deaths per accident $(<7000 \mathrm{~m}$ peaks). They include two very large events: Pik Lenin in the Pamir (1990) when an earthquake in Afghanistan triggered icefall which released a snow avalanche killing 43 of 45 climbers in Camp II, and Kang Guru (2005) in the Manaslu region of Nepal where 18 were killed in a snow avalanche at base camp. Excluding these two large events, there are 3.1 deaths per accident $(>7000 \mathrm{~m}$ peaks) and 4.0 deaths per accident ( $<7000 \mathrm{~m}$ peaks).

McClung (1981) compiled records from before 1979. When combined with the data above, the results were: $>8000$ m peaks: 216 deaths (79 accidents); and $<8000 \mathrm{~m}$ peaks: 295 deaths (83 accidents). These data imply 2.7 deaths per accident (>8000 m peaks) and 3.6 deaths per accident $(<8000 \mathrm{~m}$ peaks).

All these calculations show more deaths per avalanche accident than in North American mountaineering, where the rate is $\sim 1.9$ per accident (McClung, 1981). In addition, the data suggest that the deaths per accident average increases as the group peak altitude decreases, which is opposite to the conclusions of McClung (1981). One explanation of these trends could be that camp placement has been less safe on the peaks below $8000 \mathrm{~m}$ as explained below. The $8000 \mathrm{~m}$ peaks are better documented and routes are better known than on the lower peaks.

\section{AVALANCHE FATALITIES BY TRIGGERING MECHANISM AND ACTIVITY}

In this section, fatalities are considered as a function of triggering mechanism. The data are from McClung (1981) and the 92 cases documented from the alpine journals since
1979. Data are stratified into unknown and three other categories: icefall (including sérac collapse, ice avalanches, and snow avalanches triggered by icefall), improper camp placements (including any snow or ice event where camps were overrun), and snow avalanches triggered by or during climbing. The icefall category consists of events initiated by glacier ice which cannot be forecasted. The improper camp placement category includes people killed in camps due to errors made by climbers when placing, and residing in, them. The triggered/climbing category comprises natural snow avalanche events or events triggered by climbers. This category was retained with both types (natural and triggered) since the majority of expedition reports are insufficiently well documented or there is incomplete information about whether events are natural or triggered. For the triggered/ climbing category, there is a chance that the events could have been forecasted since snow avalanches can sometimes be forecasted (e.g. McClung and Schaerer, 2006). Table 2 summarizes 616 documented events.

By subtraction, Table 2 implies that the percentage of deaths from improper camp placement for $<8000 \mathrm{~m}$ peaks is $\sim 54 \%$, compared to $35 \%$ for $>8000 \mathrm{~m}$ peaks. Icefall deaths account for $\sim 12 \%$ of deaths for $<8000 \mathrm{~m}$ peaks, compared to $27 \%$ for $>8000 \mathrm{~m}$ peaks. Due to incomplete reporting, the numbers should be taken as only rough estimates. The important fact is that each of the three categories contains large numbers of climber fatalities in the high mountains of Asia. Further, human judgment and decisions govern the fatality statistics in these mountains. Improper camp placement and lack of good forecasting explain about threequarters of the deaths.

For comparison, $\sim 90 \%$ of snow avalanche deaths in Europe and North America are triggered by the victims (e.g. McClung and Schaerer, 2006), with $\sim 10 \%$ from natural triggers.

The immense scale (vertical relief) of the peaks, coupled with high altitudes, implies that long durations (up to months on the $>8000 \mathrm{~m}$ peaks) are needed to scale the peaks, which increases the time exposure probability of risk. Panch Chulli II (6904 m), Indian Himalaya, on which nine climbers were killed in 2003, has a vertical relief from base camp to summit of $3700 \mathrm{~m}$, although not all of this is on permanent snow cover. Thus, it is not just the $8000 \mathrm{~m}$ peaks that have great vertical relief. The fact that base camps are often at or above the altitude of the snowline (typically $4800 \mathrm{~m}$ ) means that snow and ice will be encountered over long distances to increase the spatial and temporal probability of risk. Improper camp placements (Table 2), which account for the highest number of fatalities, are hardly an issue outside expedition climbing.

\section{AVALANCHE FATALITY STATISTICS BY REGION}

It was shown above that avalanche fatalities are concentrated in central Nepal. In this section I include statistics with groupings roughly based on the larger-scale climate zone and country. The Pakistan group includes data from the Karakoram Range (including China and India) and parts of the Himalaya which extend north into Pakistan (including Nanga Parbat). In this group, the main climbing season is in the summer, when the monsoon prevents climbing in the southern Himalaya. The Nepal/Tibet group includes Nepal, Nepal/Tibet border peaks and Shisha Pangma (entirely in Tibet). The India group includes the Indian Himalaya 
Table 3. Location versus avalanche death toll (1895-2014)

Location

Number of deaths \% of total deaths

Pakistan/India/China: Karakoram;

Pakistan: Himalaya

Nepal/Tibet: Himalaya

India: Himalaya

Central Asia

Southwest China

156

413

49

62

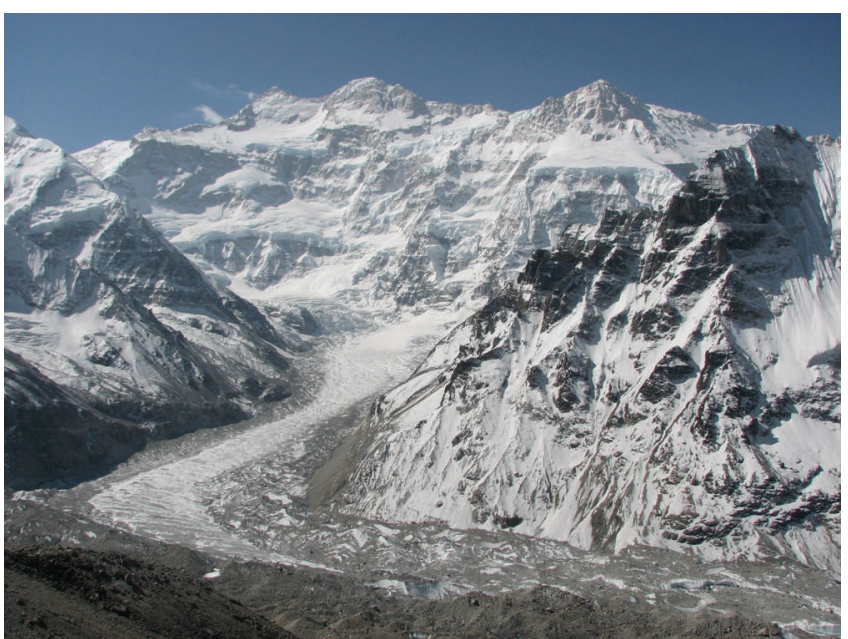

Fig. 1. Kangchenjunga (8586 ma.s.I.) from the west (Nepal). The glacier accumulation zone extends to the base of the steep slopes, implying that avalanching may be a significant source of mass balance. Snow avalanches should also be a significant source of supraglacial debris. Kangchenjunga glacier runs down-valley for $>10 \mathrm{~km}$ from the base of the mountain.

2. There are many peaks with steep faces above glaciers. For these, snow avalanching can provide a significant component of mass-balance input. Benn and Evans (1998) suggested that in the Himalaya, snow avalanching is the most important source of supraglacial debris. Virtually all large glaciers in the Himalaya and Karakoram are debris-covered in the ablation zones. Figure 1 shows the west side of Kangchenjunga, eastern Nepal. The glacier ablation zone is directly beneath the steep faces, which may imply that avalanche sources on the slopes above constitute much of the accumulation zone. The ablation zone is beneath steep avalanche-prone slopes.

3. Without data, it is not possible to conclude that snow avalanches in these mountains are larger or run further on average than in other ranges. The large vertical relief above the snowline may suggest that there is more scope for entrainment of snow in some cases to produce larger masses, but there are no data from these ranges to support this. Data from numerous sources suggest that snow avalanches release on slopes between $25^{\circ}$ and $55^{\circ}$ (McClung, 2013) and large avalanches begin to deposit on slopes around $10^{\circ}$ (McClung and Schaerer, 2006). It is unlikely that a dataset from the high Asian mountain ranges would show something different. Most mountaineering, including camps, will take place in those slope angle ranges.

4. The temporal pattern of avalanche deaths is dictated by weather and climate patterns that are favorable for climbing. In the southern Himalaya (Nepal, Tibet, India) most fatalities are in the pre- and post-monsoon seasons, when relatively good weather can be expected. In the Karakoram and northern Himalaya, fatalities are concentrated during the summer monsoon, which has little or no effect in these ranges. However, in general, the Asian peaks are so high that winter snow conditions can be found at any time of year, with brutally cold conditions in winter. 
5. Human actions and decisions govern the fatal avalanche patterns. Table 2 shows that about three-quarters of the deaths result from improper camp placements and failure to forecast snow avalanches. Failure in human perception of avalanche instability (McClung and Schaerer, 2006) is the root cause of many accidents. Good avalanche forecasting and safety requires both targeted education and experience, as well as elimination of human biases and decision traps and good interpretation of any data sampling. General prowess at climbing and physical strength are attributes of most expedition climbers, but these have nothing to do with avalanche-forecasting ability. Expedition climbing on the high peaks of Asia requires winter climbing experience plus avalanche-forecasting ability, training and basic avalanche equipment (shovel, probe, transceiver) to ensure a basic level of safety. This includes all personnel (members, porters, high-altitude porters, climbing Sherpas) who venture into snow and ice avalanche prone terrain.

6. The events from icefalls cannot, by and large, be forecasted. If icefalls must be passed, risk management has to be used to eliminate excessive exposure of people in time and space, and that includes prospective camp sites. Icefall-triggered snow avalanches have been a significant source of fatalities, which adds to the complexity of trying to forecast. It might be argued that glacier motion is accelerated after the monsoon loads the accumulation zone, but there are no data to support this in terms of fatality numbers.

7. Avalanche fatalities in the high mountains of Asia due to mountaineering-related activities are considerably less than for lower-altitude regimes such as valley bottoms in Asian countries where villages, roads and human movement occur in great numbers. The Appendix provides information to support this conclusion.

\section{ACKNOWLEDGEMENTS}

This research was supported by the University of British Columbia and the Natural Sciences and Engineering Research Council of Canada.

\section{REFERENCES}

American Alpine Journal (AAJ) (1980-2014) American Alpine Journal: 1980-2014: 92 expedition reports. http://publications. americanalpineclub.org

Benn DI and Evans DJA (1998) Glaciers and glaciation. Arnold (Hodder Headline Group), London

Dhar ON and Nandargi S (2005) Areas of heavy precipitation in the Nepalese Himalayas. Weather, 60(12), 354-356

Ganju A, Thakur NK and Rana V (2002) Characteristics of avalanche accidents in western Himalayan region, India. In Proceedings of the International Snow Science Workshop, 29 September-4 October 2002, Penticton, B.C., Canada. International Snow Science Workshop, 200-207

McClung DM (1981) Avalanche fatalities in Himalayan mountaineering. Am. Alp. J., 55(23), 138-145
McClung DM (2013) Effects of triggering mechanism on snow avalanche slope angles and slab depths from field data. Natur. Hazards, 69, 1721-1731 (doi: 10.1007/s11069-013-0771-2)

McClung DM (2014) Risk analyses for dry snow slab avalanches released by skier triggering. Natur. Hazards, 72, 1139-1158 (doi: 10.1007/s11069-014-10604)

McClung D and Schaerer P (2006) The avalanche handbook, 3rd edn. The Mountaineers Books, Seattle, WA

Podolskiy EA, Sato A and Komori J (2009) Avalanche issue in western Himalaya. Seppyo, J. Jpn. Soc. Snow Ice, 71(6), 498-502

Salisbury R (2004) The Himalayan database. The American Alpine Club, Golden, CO

Salisbury R and Hawley E (2007) The Himalaya by the numbers. The Mountaineers Books, Seattle, WA www.himalayandatabase.com

Shipton EE (1943) Upon that mountain. Hodder and Stoughton Ltd, London

\section{APPENDIX: AVALANCHE DEATHS IN INDIA AND ASIA FROM OTHER CAUSES}

Avalanche fatalities from mountaineering activities are far from the only ones in Asia. Podolskiy and others (2009) collected data from selected countries from 1995 to 2006. They showed that there were 565 fatalities in India, with data included for selected other Asian countries: Afghanistan (209), Pakistan (291), Tajikistan (151) and China (80) (Nepal was excluded). These data include people killed in villages and travelling in valley bottoms.

For India (Ganju and others, 2002) continuous records of annual death totals are available from 1970 collected by the Snow and Avalanche Study Establishment of the Indian Army. For the period 1970-2002, the records show 1428 fatalities, with $\sim 30 \%$ being from the Indian Army. I made a time-series trend analysis of the data (31 years of records). The Mann-Kendall test yielded a positive upward trend over the period, but the trend is not statistically significant $(p=0.21)$. The data are highly skewed, with mean $46 \mathrm{a}^{-1}$ and median $14 \mathrm{a}^{-1}$. Three years contain very high death tolls: 1978/79 (286), 1982/83 (233) and 1987/88 (326). I fit the data to 60 different probability distributions using five goodness-of-fit tests: Kolmogorov-Smirnoff, Anderson-Darling, chi-squared plus quantile and probability plots. The best fit was from a two-parameter lognormal distribution for which the 0.5 exceedance probability gave 16 fatalities $\mathrm{a}^{-1}$.

These data show that the biggest source of fatalities in Asian countries comes from the people in villages, on roads, the general movement of people, and army maneuvers outside of the highest mountains. The differences may be explained by the higher proportion of people at lower elevations. There is a lack of villages and roads in the elevation domain of the mountaineering activities surveyed in the present paper.

The Gayari avalanche of 2012 (http://tribune.com.pk/ story/612378/), in which 140 Pakistani army personnel were killed due to improper camp placement downstream of Bilafond glacier, is an example outside the scope of normal mountaineering activities. However, it and the accidents incurred by the Indian Army show the importance of good avalanche forecasting in military activities. 